\title{
A Study of Death Anxiety among Pre and Post Operated Cancer Patients
}

\section{ABSTRACT:}

\author{
Rajendra Patel*, Dr. Pankaj Suvera**
}

The present research work aimed at finding out the difference between pre and post cancer patients on Death anxiety. For this purpose a total sample of 200 cancer patients. Among them 100 pre and 100post operated cancer patients. Data was collected by using Death anxiety scale developed by Templer's [1970]. Results were analyzed by using F- ANOVA and t. Results revealed thatthere is no significant difference between pre and post operated cancer patient on death anxiety. There is wide difference between mean of male and female on their death anxiety.

Keywords: Death anxiety, pre and post operated cancer patients.

\section{INTRODUCTION}

A common denominator of cancer patients is their fear of death, regardless of personal characteristics, religious beliefs or cultural background. Although Muslims, Hindu, Krishnan etc. believe in life after death, fear of death exists in the culture even though it is a natural human experience. When patients are diagnosed with cancer, as opposed to other diseases, patients may have a greater fear of death. The cancer patient might be unique in the fact that the fear might come from the meaning that the patients attach to the word cancer and its association with death (Vilhuer, 2008).

Vilhuer also states that most patients have a fear of the unknown. Once the diagnosis of cancer has been made, patients start to experience feelings of fear, stress, depression, and worry of what the future holds for their lives. Researchers suggest that cancer and depression are related (Rodgers, Martin, Morse, Kendall, \& Verrill, 2005). Death distress and anxiety level are associated with depression. This constant fear creates anxiety and depression which can affect day -to- day life and can become very distressing.

Pasquini and Biondi (2007) concluded that depression causes complications in the course of cancer and its treatment. It is not only the diagnosis of cancer that is related to the depression rate, but also the amount of pain the cancer patient feels, the socioeconomic issues, the religious beliefs or cultural attitudes toward the disease, and the ability to follow through on treatments -

\footnotetext{
*Research Scholar, Dept. of Psychology, Sardar Patel University, Vallbh Vidhyanagar, Gujarat, India

**Assi. Professor, Dept. of Psychology, Sardar Patel University, Vallbh Vidhyanagar, Gujarat, India

(C) 2014 R Patel, P Suvera; licensee IJIP. This is an Open Access Research distributed under the terms of the Creative Commons Attribution License (http://creativecommons.org/licenses/by/2.0), which permits unrestricted use, distribution, and reproduction in any Medium, provided the original work is properly cited.
} 
- that can all lead the patients to face this kind of stress (Vilhuer, 2008). Among people who have been diagnosed with cancer, patients with high levels of pain have much higher rates of depression than those with little or no pain (Tavoli, Montezeri, Rasook, Tavoli, \&Mahdiyeh, 2008).

The majority of cancer patients have similar fears; fear of pain, death, loss of control and function. These fears may lead to suffering and depression; it is easy to understand the difficulty faced by cancer patients when they have to live their lives with the threat of their impending death always present (Sigal et al., 2008).death is a mysterious concept which also creates curiosity which defines the end of the life of the living and create no-occurrence, uncertainty, fear, despair and lack of hope, it is a constantly researched phenomenon. Death and the effort to solve its mystery has led to the effort of solving the secret of mortality and getting an absolute guarantee of existence. Attitudes, thoughts and behaviors towards death also show the life perspective of the individual and it show how that individual perceives life. Term of death anxiety refers not to the anxiety which is felt in the case of an urgent threat towards a person's life; it refers to the anxiety experienced in "daily life". Yalom (2000) says, "The fear of death exists always and everywhere and it is so great that, most of the life energy is spent in the moment of death (Yalom, 2000).Basically the thing that scares the individual is not the feeling that life will continue, but it is the feeling that it will end at some point. Deaths do not come to humankind in the normal flow of life. However, he/she feels it if he/she witnesses some events around him/her which could lead to death. Each individual's source of death anxiety may not bethe same. According to Imam, the death anxiety is stated not to be cultural, it is taught and it is not an anxiety coming "from the genes", death is stated to be always included in life and life is stated to be included in death.

\section{RESEARCH PROBLEM:}

"A Study of Death anxiety among Pre and Post operated Cancer Patients"

\section{OBJECTIVES}

1. To study of the death anxiety among pre and post operated cancer patients.

2. To study of the death anxiety among male and female cancer patients.

3. To study of the death anxiety among low, medium and high age of cancer patients.

4. To study of the death anxiety among blood and other cancer patients.

5. To study of the death anxiety among low, medium and high education qualification of the cancer patients.

6. To study of the death anxiety among urban and rural area of the cancer patients.

7. To study of the death anxiety among joint and nuclear family of the cancer patients.

8. To study of the death anxiety among low, medium, high income of the cancer patients. 


\section{HYPOTHESIS}

1. There is no difference between death anxiety of pre and post operated cancer patients.

2. There is no difference between death anxiety of Male and female of the cancer patients.

3. There is no interaction effect of death anxiety on types of patients and sex of the cancer patients.

4. There is no difference between death anxiety of low and medium age of the cancer patients.

5. There is no difference between death anxiety of low and high age of the cancer patients.

6. There is no difference between death anxiety of medium and high age of the cancer patients.

7. There is no difference between death anxiety of blood and other cancer patients.

8. There is no difference between of death anxiety low and medium education of the cancer patients.

9. There is no difference between death anxiety of low and high education of the cancer patients.

10. There is no difference between death anxiety of medium and high education of the cancer patients.

11. There is no difference between death anxiety of urban and rural area of the cancer patients.

12. There is no difference between death anxiety of joint and nuclear family of the cancer patients.

13. There is no difference between death anxiety of low and medium income of the cancer patients.

14. There is no difference between death anxiety of low and high income of the cancer patients.

15. There is no difference between death anxiety of medium and high income of the cancer patients.

\section{SELECTION OF SAMPLE:}

Sampling is a powerful tool in social research. Sampling procedures make it possible to know how much confidence one can have that the information gathered is similar to the information that would have been gathered if one had studied everyone in the larger group.

In this research study of pre and post operated cancer patients shall be select from central Gujarat and these rural and urban area. This sample will select by random sampling method A total of 200 cancer patients selected out of which 100 pre operated and 100 post operated Cancer patients out of which 50 male and 50 female cancer patient's taken. Sample taken from hospital and NGO of Anand, Baroda, Ahemdabad, Dharmaj, Balasinor cites.

\section{RESEARCH TOOLS:}

For this study to collect the required information the following toots shall be used.

\section{Personal data sheet:}

A personal data sheet developed by investigator was used to collect information about types of patients, sex, age, types of cancer, education, area, types of family, income etc. 


\section{SCALES:}

\section{- Death anxiety scale:}

Death anxiety scale developed by Templer's[1970] was used to measure death anxiety the scale contains 15 items with two, true and false response alterative the maximum possible score is zero high score indicates high level of death anxiety and low score indicated low level of death anxiety Templer has reported a test-retest reliability coefficient is 0.83 and internal consistency coefficient is 0.76 the author has report satisfactory validity of the questionnaire the Gujarat version used in the present study had correlation between 0.94 with the original English vision.

The scoring keys presentable below each time one of your responses corresponds to the command assurers. Give yours self and paint then add $u$ the total number of paint for your scores.

$\begin{array}{lllll}\text { 1. True } & 6 & \text { F } & 11 & \text { T } \\ \text { 2. False } & 7 & \text { F } & 12 & \text { F } \\ \text { 3. F } & 8 & \text { T } & 13 & \text { T } \\ \text { 4. F } & 9 & \text { T } & 14 & \text { T } \\ \text { 5. F } & 10 & \text { T } & 15 & \text { F }\end{array}$

The nature for inter berthing your score and this scale are bared and a sample of 1,2,71 adults cited by lonetlo and Templar (1983).

\section{High score - 9-15}

\section{Medium score - 4-8}

Table no. 1.1, 2x2 ANOVA Analysis summary of Death anxiety with reference to types of patients and sex of the cancer patients $(\mathrm{N}=200)$

\begin{tabular}{|c|c|c|c|c|}
\hline $\begin{array}{c}\text { Source of } \\
\text { variance }\end{array}$ & $\begin{array}{c}\text { Sum of } \\
\text { Square }\end{array}$ & $\mathrm{df}$ & $\begin{array}{c}\text { Mean Sum } \\
\text { of Square }\end{array}$ & $\mathrm{F}$ \\
\hline $\begin{array}{c}\text { Types of } \\
\text { patients (A) }\end{array}$ & 0.00 & 1 & 0.00 & $0.00(\mathrm{NS})$ \\
\hline Sex(B) & 9.68 & 1 & 9.68 & $1.03(\mathrm{NS})$ \\
\hline $\begin{array}{c}\text { T of P (A) } \\
\text { Sex (B) }\end{array}$ & 144.50 & 1 & 144.50 & $15.12(0.01)$ \\
\hline SSW(Error) & 1872.84 & 196 & 9.55 & \\
\hline SST & 2027.02 & 199 & & \\
\hline
\end{tabular}


Table no. 1.2, Difference between mean scores of Death anxiety with reference to types of patients and sex of the cancer patients $(\mathrm{N}=200)$

\begin{tabular}{|c|c|c|c|}
\hline Independent variable & $\mathrm{n}$ & Mean(M) & $\begin{array}{c}\text { Difference } \\
\text { between mean }\end{array}$ \\
\hline Pre operated cancer patients & 100 & 8.57 & 0.00 \\
\hline Post operated cancer patients & 100 & 8.57 & \multirow{2}{*}{0.44} \\
\hline Male & 100 & 8.79 & 8.35 \\
\hline Female & 100 &
\end{tabular}

\section{With reference to types of cancer patients}

Null hypothesis Ho.No.1 was constructed to get information whether any significant difference exist Death anxiety of pre and post operated cancer patients.

\section{Ho.1:- There is no difference between Death anxiety of pre and post operated cancer patients.}

It can be observed that the table no. 1.1 that " $F$ " value with reference to Death anxiety of pre and post operated cancer patients was 0.00 this "F" value is not significant. So, null hypothesis 1 is accepted. And the result shows not significant difference. It can be seen the table no. 1.2 that the mean of scores of pre and post operated cancer patients were 8.57 and 8.57 respectively. The difference between mean of Death anxiety of pre and post operated cancer patients is 0.00 . So it can be no difference between Death anxiety of pre and post operated cancer patients.

\section{Death anxiety with reference to sex of the cancer patients}

Null hypothesis Ho.No.2 was constructed to get information whether any significant difference between male and female of the cancer patients.

Ho.2:- There is no difference between Death anxiety of male and female of the cancer patients.

It can be seen the table no. 1.1 that "F" value with reference to religious behaviour of male and female was 9.68 this "F" value is not significant. So, null hypothesis 2 is accepted. The result shows not significant difference. And it can be seen the table no.1.2 that the mean scores of Death anxiety of male and female were 8.79 and 8.35 respectively. The difference between mean of Death anxiety of male and female is 0.44 . So it can be said that there is wide difference between mean of male and female on their death anxiety.

Death anxiety with reference to interaction between types of patients and sex of the cancer patients

Null hypothesis Ho.No.3 was constructed to get information whether any effect exist on Death anxiety as a result of interaction to each other types of patients and sex of the cancer patients.

Ho.3:- There is no interaction effect of Death anxiety on types of patients and sex of the cancer patients. 
"F" value obtained while examining hypothesis to get information regarding effect of interaction with reference to Death anxiety of types of patients and sex of the cancer patients. It can be seen the table no.1.1 the "F" value is 15.12 this " $F$ " value is significant at 0.01 levels. So above null hypothesis is rejected. And the result show significant effect of Death anxiety on types of patients and sex of the cancer patients.

\section{DEATH ANXIETY, WITH REFERENCE TO AGE, TYPES OF CANCER, TYPES OF EDUCATION, AREA, TYPES OF FAMILY, INCOME}

Table no 1.3, Means and SDs of death anxiety with reference to low and medium age of the cancer patients, $(\mathrm{N}=200)$

\begin{tabular}{|c|c|c|c|c|}
\hline Age & N & Mean & SD & t \\
\hline Low & 64 & 8.52 & 3.30 & 0.05 \\
Medium & 76 & 8.49 & 3.18 & NS \\
\hline \multicolumn{5}{|c|}{ NS= Not Significant } \\
\hline
\end{tabular}

\section{Death anxiety with reference to age of the cancer patients. (Low and medium)}

Null hypothesis Ho.No.4 was constructed to get information whether any significant difference between death anxiety of low and medium age of the cancer patients.

Ho.4:- There is no difference between the death anxiety of low and medium age of the cancer patients.

It can be observed the table no. 1.3 that mean scores with reference death anxiety of low and medium age of the cancer patients were 8.52 and 8.49. The difference between "t" values is 0.05 . That " $\mathrm{t}$ " value is not significant. It can be seen the table no 4.52 there was no more difference between mean of two group. So, null hypothesis 4 is accepted. And the result shows there is negligible difference between low and medium age of the cancer patients on their death anxiety.

Table no 1.4, Means and SDs of death anxiety with reference to low and high age of the cancer patients $(\mathrm{N}=200)$

\begin{tabular}{|c|c|c|c|c|}
\hline Age & N & Mean & SD & t \\
\cline { 1 - 3 } Low & 64 & 8.52 & 3.30 & 0.38 \\
\cline { 1 - 2 } High & 60 & 8.73 & 3.14 & NS \\
\hline \multicolumn{5}{|c|}{ NS= Not Significant } \\
\hline
\end{tabular}

\section{Death anxiety with reference to age of the cancer patients. (Low and high)}

Null hypothesis Ho.No.5 was constructed to get information whether any significant difference between death anxiety of low and high age of the cancer patients.

Ho5:- There is no difference between the death anxiety of low and high age of the cancer patients. 
It can be observed the table no. 1.4 that mean scores with reference death anxiety of low and high age of the cancer patients were 8.52 and 8.73 . The difference between " $t$ " values is 0.38 . That " $\mathrm{t}$ " value is not significant. It can be seen the table no 1.4 there was no more difference between mean of two group. So, null hypothesis 5 is accepted. And the result shows there is negligible difference between low and high age of the cancer patients on their death anxiety.

Table no 1.5, Means and SDs of death anxiety with reference to medium and high age of the cancer patients $(\mathrm{N}=200)$

\begin{tabular}{|c|c|c|c|c|}
\hline Age & N & Mean & SD & t \\
\cline { 1 - 3 } Medium & 76 & 8.49 & 3.18 & 0.45 \\
High & 66 & 8.73 & 3.14 & NS \\
\hline \multicolumn{4}{|c|}{ NS= Not Significant } \\
\hline
\end{tabular}

\section{Death anxiety with reference to age of the cancer patients (Medium and high)}

Null hypothesis Ho.No.6 was constructed to get information whether any significant difference between death anxiety of medium and highage of the cancer patients.

Ho.6:- There is no difference between the death anxiety of medium and high age of the cancer patients.

It can be observed the table no. 1.5 that mean scores with reference death anxiety of medium and highage of the cancer patients were 8.49 and 8.73. The difference between " $t$ " values is 0.45 . That " $\mathrm{t}$ " value is not significant. It can be seen the table no 1.5 there was no more difference between mean of two group. So, null hypothesis 6 is accepted. And the result shows there is negligible difference between medium and high age of the cancer patients on their death anxiety.

Table no 1.6, Means and SDs of death anxiety with reference to blood and other's cancer $(\mathrm{N}=200)$

\begin{tabular}{|c|c|c|c|c|}
\hline Types of cancer & $\mathbf{N}$ & Mean & SD & t \\
\hline Blood & 40 & 7.13 & 3.19 & 3.28 \\
Other's & 160 & 8.93 & 3.10 & $(0.01)$ \\
\hline \multicolumn{5}{|c|}{0.01 level } \\
\hline
\end{tabular}

\section{Death anxiety with reference to types of cancer (blood and other's cancer)}

Null hypothesis Ho.No.7 was constructed to get information whether any significant difference between death anxiety of blood and other cancer.

\section{GRAPH}

Mean of Death anxiety with reference to blood cancer and other's cancer patients.

$\mathrm{X}=$ types of cancer (blood \& other's cancer)

$\mathrm{Y}=1 \mathrm{~cm}=2$ average score 


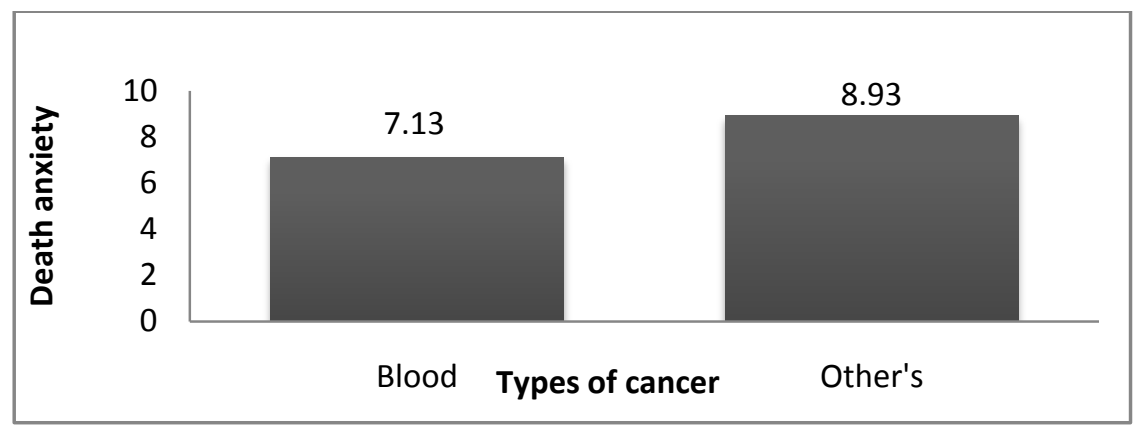

Ho.7:- There is no difference between the death anxiety of blood and other cancer.

It can be observed the table no. 1.6 that mean scores with reference death anxiety of blood and other cancer were 7.13 and 8.93. The difference between " $t$ " values is 3.28. That " $t$ " value is significant at 0.01 level. It can be seen the table no 1.6 there was no more difference between mean of two group. So, null hypothesis 7 is rejected. And the result shows there is negligible difference between blood and other cancer on their death anxiety.

Table no 1.7, Means and SDs of death anxiety with reference to low and medium education of the cancer patients $(\mathrm{N}=200)$

\begin{tabular}{|c|c|c|c|c|}
\hline $\begin{array}{c}\text { Types of } \\
\text { Education }\end{array}$ & N & Mean & SD & t \\
\hline Low & 61 & 8.28 & 3.10 & 1.28 \\
\cline { 1 - 3 } Medium & 94 & 8.95 & 3.23 & NS \\
\hline \multicolumn{4}{|c|}{ NS= Not Significant } \\
\hline
\end{tabular}

\section{Death anxiety with reference to education of the cancer patients (low and medium)}

Null hypothesis Ho.No.8 was constructed to get information whether any significant difference between religious behavior of low and medium education of the cancer patients.

Ho.8:- There is no difference between the death anxiety of low and medium education of the cancer patients.

It can be observed the table no. 1.7 that mean scores with reference death anxiety of low and medium education of the cancer patients were 8.28 and 8.95 . The difference between " $t$ " values is 1.28. That " $t$ " value is not significant. It can be seen the table no 1.7 there was no more difference between mean of two group. So, null hypothesis 8 is accepted. And the result shows there is negligible difference between low and medium education of the cancer patients on their death anxiety. 
Table no 1.8, Means and SDs of death anxiety with reference to low and high education of the cancer patients $(\mathrm{N}=200)$

\begin{tabular}{|c|c|c|c|c|}
\hline $\begin{array}{c}\text { Types of } \\
\text { Education }\end{array}$ & N & Mean & SD & t \\
\hline Low & 61 & 8.28 & 3.10 & 0.16 \\
\cline { 1 - 3 } High & 45 & 8.18 & 3.22 & NS \\
\hline \multicolumn{5}{|c|}{ NS= Not Significant } \\
\hline
\end{tabular}

\section{Death anxiety with reference to education of the cancer patients, (low and high)}

Null hypothesis Ho.No.9 was constructed to get information whether any significant difference between religious behavior of low and high education of the cancer patients.

Ho.9:- There is no difference between the death anxiety of low and high education of the cancer patients.

It can be observed the table no. 1.8that mean scores with reference death anxiety of low and high education of the cancer patients were 8.28 and 8.18. The difference between " $t$ " values is 0.16 . That " $\mathrm{t}$ " value is not significant. It can be seen the table no 1.8 there was no more difference between mean of two group. So, null hypothesis 9is accepted. And the result shows there is negligible difference between low and high education of the cancer patients on their death anxiety.

Table no 1.9, Means and SDs of death anxiety with reference to medium and high education of the cancer patients $(\mathrm{N}=200)$

\begin{tabular}{|c|c|c|c|c|}
\hline $\begin{array}{c}\text { Types of } \\
\text { Education } \\
\text { Medium }\end{array}$ & 94 & 8.95 & 3.23 & Mean \\
\hline High & 45 & 8.18 & 3.22 & NS \\
\hline \multicolumn{4}{|c|}{ NS= Not Significant } \\
\hline
\end{tabular}

\section{Death anxiety with reference to education of the cancer patients. (medium and high)}

Null hypothesis Ho.No.10 was constructed to get information whether any significant difference between religious behavior of medium and high education of the cancer patients.

Ho.10:- There is no difference between the death anxiety of medium and high education of the cancer patients.

It can be observed the table no. 1.9 that mean scores with reference death anxiety of medium and high education of the cancer patients were 8.95 and 8.18 . The difference between " $t$ " values is 1.32. That " $\mathrm{t}$ " value is not significant. It can be seen the table no 1.9 there was no more difference between mean of two group. So, null hypothesis 10 is accepted. And the result shows there is negligible difference between medium and high education of the cancer patients on their death anxiety. 
Table no 1.10. Means and SDs of death anxiety with reference urban and rural area of the cancer patients $(\mathrm{N}=200)$

\begin{tabular}{|c|c|c|c|c|}
\hline Area & N & Mean & SD & t \\
\hline Urban & 62 & 8.44 & 3.62 & 0.40 \\
\cline { 1 - 3 } Rural & 138 & 8.63 & 2.99 & NS \\
\hline \multicolumn{5}{|c|}{ NS= Not Significant } \\
\hline
\end{tabular}

\section{Death anxiety with reference to area of the cancer patients. (Urban and rural)}

Null hypothesis Ho.No.11 was constructed to get information whether any significant difference between death anxiety of urban and rural area of the cancer patients.

Ho.11:- There is no difference between the death anxiety of urban and rural area of the cancer patients.

It can be observed the table no. 1.10 that mean scores with reference death anxiety of urban and rural area of the cancer patients were 8.44 and 8.63. The difference between " $t$ " values is 0.40 . That " $\mathrm{t}$ " value is not significant. It can be seen the table no 1.10 there was no more difference between mean of two group. So, null hypothesis 11 is accepted. And the result shows there is negligible difference between urban and rural area of the cancer patients on their death anxiety.

Table no 1.11

Means and SDs of death anxiety with reference to joint and nuclear family of the cancer patients $(\mathrm{N}=200)$

\begin{tabular}{|c|c|c|c|c|}
\hline Types of Family & N & Mean & SD & t \\
\hline Joint & 95 & 7.98 & 2.94 & 2.53 \\
Nuclear & 105 & 9.11 & 3.33 & $(0.05)$ \\
\hline \multicolumn{4}{|c|}{0.05 level } \\
\hline
\end{tabular}

\section{Death anxiety with reference to family of the cancer patients. (Joint and nuclear)}

Null hypothesis Ho.No.12 was constructed to get information whether any significant difference between death anxiety of joint and nuclear family of the cancer patients.

Mean of Death anxiety with reference to joint and nuclear family of the cancer patients.

$$
\mathrm{X}=\text { types of family (Joint \& nuclear) }
$$

$\mathrm{Y}=1 \mathrm{~cm}=1$ average mean score 


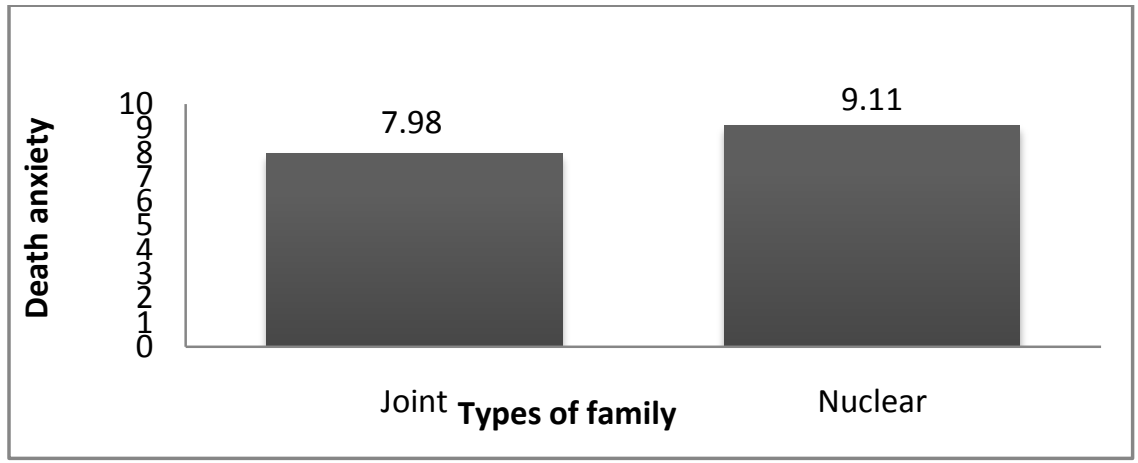

Ho.12:- There is no difference between the death anxiety of joint and nuclear family of the cancer patients.

It can be observed the table no. 1.11 that mean scores with reference death anxiety of joint and nuclear family of the cancer patients were 7.98 and 9.11. The difference between " $\mathrm{t}$ " values is 2.53. That " $t$ " value is significant at 0.05 level. It can be seen the table no 1.11 there was more difference between mean of two group. So, null hypothesis 12 is rejected. And the result shows there is wide difference between joint and nuclear family of the cancer patients on their death anxiety.

Table no 1.12, Means and SDs of death anxiety with reference to low and medium income of the cancer patients $(\mathrm{N}=200)$

\begin{tabular}{|c|c|c|c|c|}
\hline Age & N & Mean & SD & t \\
\hline Low & 88 & 8.26 & 3.25 & 0.32 \\
\cline { 1 - 3 } Medium & 63 & 8.43 & 2.97 & NS \\
\hline \multicolumn{5}{|c|}{ NS= Not Significant } \\
\hline
\end{tabular}

\section{Death anxiety with reference to income of cancer patients (low and medium)}

Null hypothesis Ho.No.13 was constructed to get information whether any significant difference between death anxiety of low and medium income of the cancer patients.

Ho.13:- There is no difference between the death anxiety of low and medium income of the cancer patients.

It can be observed the table no. 1.13 that mean scores with reference death anxiety of low and medium income of cancer patients were 8.26 and 8.43. The difference between " $t$ " values is 0.32 . That " $t$ " value is not significant. It can be seen the table no 1.12 there was no more difference between mean of two group. So, null hypothesis 13 is accepted. And the result shows there is negligible difference between low and medium income of the cancer patients on their death anxiety. 
Table no 1.13, Means and SDs of death anxiety with reference to low and high income of the cancer patients $(\mathrm{N}=200)$

\begin{tabular}{|c|c|c|c|c|}
\hline Age & N & Mean & SD & t \\
\hline Low & 88 & 8.26 & 3.25 & 1.79 \\
High & 49 & 9.31 & 3.31 & NS \\
\hline \multicolumn{5}{|c|}{ NS= Not Significant } \\
\hline
\end{tabular}

\section{Death anxiety with reference to income of the cancer patients (low and high)}

Null hypothesis Ho.No.14 was constructed to get information whether any significant difference between death anxiety of low and high income of the cancer patients.

Ho.14:- There is no difference between the death anxiety of low and high income of the cancer patients.

It can be observed the table no. 1.13 that mean scores with reference death anxiety of low and high income of the cancer patients were 8.26 and 9.31. The difference between " $t$ " values is 1.79. That " $t$ " value is not significant. It can be seen the table no 1.13 there was no more difference between mean of two group. So, null hypothesis 14 is accepted. And the result shows there is negligible difference between low and high income of the cancer patients on their death anxiety.

Table no 1.14, Means and SDs of death anxiety with reference to medium and high income of the cancer patients $(\mathrm{N}=200)$

\begin{tabular}{|c|c|c|c|c|}
\hline Age & N & Mean & SD & t \\
\hline Medium & 63 & 8.43 & 2.97 & 1.48 \\
\cline { 1 - 3 } High & 49 & 9.31 & 3.31 & NS \\
\hline \multicolumn{5}{|c|}{ NS= Not Significant } \\
\hline
\end{tabular}

\section{Death anxiety with reference to income of the cancer patients (medium and high)}

Null hypothesis Ho.No.15 was constructed to get information whether any significant difference between death anxiety of medium and high income of the cancer patients.

Ho.15:- There is no difference between the death anxiety of medium and high income of the cancer patients.

It can be observed the table no. 1.14 that mean scores with reference death anxiety of medium and high income of the cancer patients were 8.43 and 9.31. The difference between " $t$ " values is 1.48. That " $\mathrm{t}$ " value is not significant. It can be seen the table no 1.14 there was more difference between no mean of two group. So, null hypothesis 15 is accepted. And the result shows there is negligible difference between medium and high income of the cancer patients on their death anxiety. 


\section{REFERENCE:}

1. Pasquini, M., \&Biondi, M. (2007), Depression in cancer patients: A critical review. Clinical Practice and Epidemiology in Mental Health, 3( 2), 1745-0179

2. Rodgers, J., Martin, C., Morse, R., Kendell, K., \&Verrill, M. (2005),An investigation into the psychometric properties of the Hospital: Anxiety and Depression Scale in patients with breast cancer. Health and Quality of Life Outcomes, 3, 41.

3. Sigal, J., Ouimet, M., Margolese, R., Panarello, L., Stibernik, V., \&Bescec, S. (2008). How patients with less-advanced and more-advanced cancer deal with three death-related fears: An exploratory study. Journal of Psychosocial Oncology, 26(1), 53-68.

4. Tavoli, A., Montazerim A., Roshan, R., Tavoli, Z., \&Melyani, M. (2008), Depression and quality of life in cancer patients with and without pain: The role of pain,beliefs. BioMed Central Cancer, (8)177, doi: 10.1186/1471-2407-8-177to manage uncertainty and threat associated with political conservatism or ideological extremity? Personality and Social Psychology Bulletin, 33, 989-1007.

5. Vilhauer, R. (2008), A qualitative study of the experiences of women with metastatic

6. Yalom I (2000), Existential Psychology, (trans. Zi Allergy), Istanbul, Kabalci Publications. p.70.

7. Yalom, I. D. (1980),Existential psychotherapy. New York: Basic Books. Zeyrek, E. Y. (2006), Death anxiety and a Taoist orientation in two cultures. Perceptual and Motor Skills, $103,70-78$. 